ARTIKEL

NILAI-NILAI EDUKATIF PANTUN DALAM TUNJUK AJAR MELAYU KARYA

TENAS EFFENDY (KAJIAN SOSIOLOGI SASTRA)

Oleh

Hasni Raudati

NIM 2121210004

Dosen Pembimbing Skripsi

Dr. Abdurrahman Adisaputera, M.Hum.

Telah Diverifikasi dan Dinyatakan Memenuhi Syarat untuk Diunggah pada Jurnal Online

Menyetujui :

Editor,

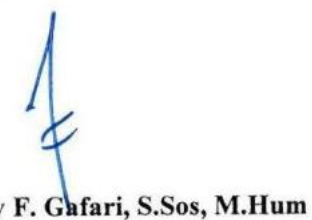

Dr. M. Oky F. Gharari, S.Sos, M.Hum NIP. 1979011522005011002
Medan, Juli 2018

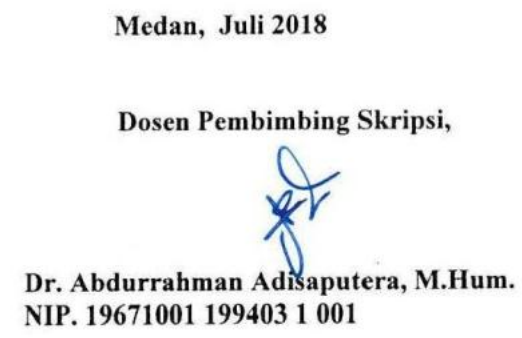

Dr. Abdurrahman Adisaputera, M.Hum. NIP. 196710011994031001 


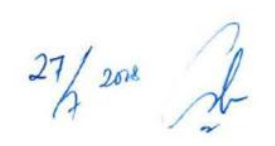

\title{
NILAI-NILAI EDUKATIF PANTUN DALAM TUNJUK AJAR MELAYU KARYA TENAS EFFENDY (KAJIAN SOSIOLOGI SASTRA)
}

\author{
Oleh \\ Hasni Raudati (hasniraudati1@gmail.com) \\ Dr. Abdurrahman Adisaputera, M.Hum. (abas_750@yahoo.co.id)
}

Penelitian ini bertujuan untuk menjelaskan nilai-nilai edukatif yang terdapat pada pantun dalam Tunjuk Ajar Melayu karya Tenas Effendy dan menentukan nilai edukatif yang paling dominan. Nilai-nilai edukatif yang dimaksud adalah nilai edukatif religius, nilai edukatif moral, nilai edukatif sosial, dan nilai edukatif budaya. Adapun metode penelitian yang digunakan adalah kualitatif deksriptif.

Hasil perolehan data ditemukan bahwa pantun dalam Tunjuk Ajar Melayu karya Tenas Effendy termasuk jenis pantun nasehat. Di dalam pantun-pantun tersebut terdapat satu pantun yang mengandung nilai edukatif religius, 19 pantun mengandung nilai edukatif moral, 3 pantun mengandung nilai edukatif sosial, dan 4 pantun mengandung nilai edukatif budaya. Dari data yang diperoleh diketahui bahwa pantun-pantun dalam Tunjuk Ajar Melayu karya Tenas Effendy lebih mengutamakan pendidikan moral tentang bagaimana seharusnya bersikap dan bertingkah laku sehari-hari baik dalam kehidupan pribadi ataupun bermasyarakat. Oleh karena itu, maka dapat diketahui bahwa nilai edukatif yang paling dominan adalah nilai edukatif moral.

\section{Kata kunci: Nilai Edukatif, Pantun, Tunjuk Ajar Melayu, Sosiologi Sastra}

\section{PENDAHULUAN}

Sastra merupakan kegiatan kreatif dan imajinatif. Sebagai kegiatan kreatif karya sastra adalah sebuah seni bahasa. Sastra juga merupakan luapan emosi secara spontan (Luxemburg, 1992: 5). Hal ini berarti setiap orang dapat melihat realitas sosial budaya dalam sebuah karya sastra bahkan dapat menjadi representasi terhadap kebudayaan masyarakat tertentu. Dengan demikian, dapat dikatakan bahwa karya sastra pada hakikatnya merupakan karya seni yang bermedia atau berbahan utama bahasa. 
Menurut Sudrajat (2012: 22) nilai edukatif merupakan nilai-nilai pendidikan yang di dalamnya mencakup sikap individu dalam kehidupan pribadi maupun kehidupan sosial. Nilai edukatif (pendidikan) merupakan segala sesuatu yang baik maupun buruk yang berguna bagi kehidupan manusia yang diperoleh melalui proses pengubahan sikap dan tata laku dalam upaya mendewasakan diri manusia melalui upaya pengajaran. Dalam hal ini upaya pengajaran yang dilakukan adalah melalui pantun.

Pesatnya perkembangan ilmu pengetahuan dan teknologi tidak saja menyebabkan dunia terasa mengecil, tetapi membawa berbagai perubahan dalam tatanan kehidupan manusia. Perkembangan itu menyebabkan terjadinya pergeseran dan perubahan nilai-nilai budaya, mulai dari perkotaan sampai ke ceruk-ceruk perkampungan. Sejalan dengan hal itu, kehidupan tradisional semakin ditinggalkan orang. Ilmu dan teknologi canggih yang diserap secara mentahmentah tidak mustahil dapat menjebak manusia dalam pergeseran dan perubahan pola pikir dan perilaku yang melecehkan nilai-nilai luhur agama, budaya, dan norma-norma sosial yang terdapat dalam masyarakat. Akibatnya, mereka dapat kehilangan nilai-nilai luhur itu yang lambat laun dapat pula menyebabkan hilangnya kepribadian dan jati diri seseorang. Oleh karena itu,orang tua-tua Melayu menegaskan, apapun wujud dan jenis ilmu yang dianut wajiblah di saring dahulu dengan ukuran akidah Islam dan diserasikan pula dengan nilai-nilai luhur budaya dan norma-norma sosial.

Banyak media yang dulu dimanfaatkan orang Melayu untuk mewariskan tunjuk ajarnya sekarang mulai lenyap atau dilupakan orang, seperti cerita-cerita rakyat, pantun, syair, gurindam, ungkapan, dan sebagainya. Di dalam penelitian ini akan disajikan analisis tentang nilai-nilai edukatif yang berfokus hanya pada pantun dalam buku Tunjuk Ajar Melayu karya Tenas Effendy.

Pantun bagi masyarakat Melayu menempati kedudukan yang baik, karena dianggap sangat bermanfaat dalam kehidupan mereka. Manfaat pantun selain sebagai hiburan adalah menyampaikan pesan-pesan moral dan nilai-nilai luhur agama, budaya, dan norma-norma sosial yang dianut masyarakatnya (Effendy, 2005: 14). Pantun harus berperan untuk menyampaikan pesan-pesan moral yang 
berisi nilai-nilai luhur agama, budaya, dan norma-norma sosial masyarakat. Oleh karena itu, pantun harus bersifat mengingatkan, tunjuk ajar, nasehat, tidak boleh memfitnah, merendahkan martabat orang lain, dan lain sebagainya yang bersifat negatif.

Kurangnya penerapan nilai-nilai edukatif di dalam karya sastra saat ini menjadi alasan peneliti untuk mengangkat kembali kajian pantun sehingga masyarakat dapat mengenal pantun bukan hanya untuk hiburan tetapi juga dapat memberikan pendidikan yang bermanfaat. Oleh karena itu, untuk mempelajari pantun-pantun yang mengandung tunjuk ajar dan memiliki nilai-nilai edukatif di dalamnya dapat ditemukan dalam buku Tunjuk Ajar Melayu karya Tenas Effendy yang juga menjadi objek penelitian.

Meninjau dari latar belakang di atas, penulis tertarik dengan pengkajian nilai-nilai edukatif yang terkandung dalam pantun peneliti memberikan judul penelitian "Nilai-Nilai Edukatif Pantun dalam Tunjuk Ajar Melayu karya Tenas Effendy (Kajian Sosiologi Sastra).

\section{METODE PENELITIAN}

Metode yang digunakan dalam penelitian ini adalah metode penelitian kualitatif deskriptif dengan metode content analysis atau analisis isi. Menurut Bogdan dan Taylor (dalam Moleong, 2012: 4) metode kualitatif merupakan prosedur penelitian yang menghasilkan data deskriptif berupa kata-kata tertulis atau lisan dai orang-orang dan perilaku yang dapat diamati. Penelitian kualitatif sangat mempertahankan hakikat nilai-nilai.

Metode ini dipilih karena data yang digarap adalah kata-kata, kalimatkalimat, dan bukan angka-angka. Penelitian ini ditekankan pada pendeskripsian nilai-nilai edukatif pantun dalam Tunjuk Ajar Melayu karya Tenas Effendy. Penelitian ini mendeskripsikan apa yang menjadi masalah, kemudian menganalisis dan menafsirkan data yang ada, dalam penelitian ini data-data yang dimaksud adalah buku Tunjuk Ajar Melayu karya Tenas Effendy. 


\section{HASIL PENELITIAN DAN PEMBAHASAN}

\section{A. Hasil Penelitian}

1. Nilai-Nilai Edukatif yang Terdapat pada Pantun dalam Tunjuk Ajar Melayu karya Tennas Effendy

Tabel 1 Hasil Analisis Pantun

\begin{tabular}{|c|c|c|c|c|c|}
\hline No. & Cuplikan Teks & Religius & Moral & Sosial & Budaya \\
\hline 1. & $\begin{array}{l}\text { Buah kelat di tengah halaman } \\
\text { Pagi hari jatuh ke pangkal } \\
\text { Bertuah umat karena beriman } \\
\text { Bertuah diri karena beramal }\end{array}$ & $\sqrt{ }$ & & & \\
\hline 2. & $\begin{array}{l}\text { Apalah tanda punak berbuah } \\
\text { Dari jauh nampak putiknya } \\
\text { Apalah tanda anak bertuah } \\
\text { Budi senonoh nampak cerdiknya }\end{array}$ & & $\sqrt{ }$ & & \\
\hline 3. & $\begin{array}{l}\text { Kalau hendak meniup puntung } \\
\text { Elok-elok menjaga apinya } \\
\text { Kalau hendak hidup beruntung } \\
\text { Elok-elok menjaga pekertinya }\end{array}$ & & $\sqrt{ }$ & & \\
\hline 4. & $\begin{array}{l}\text { Kalau hendak pergi ke kuala } \\
\text { Bawalah jermal beserta pukat } \\
\text { Kalau hendak berbudi mulia } \\
\text { Banyakkan amal serta ibadat }\end{array}$ & & $\sqrt{ }$ & & \\
\hline 5. & $\begin{array}{l}\text { Kalau angin bertiup di darat } \\
\text { Ambillah jala turunkan sampan } \\
\text { Kalau hidup hendak selamat } \\
\text { Ayah dan bunda kita muliakan }\end{array}$ & & $\sqrt{ }$ & & \\
\hline 6. & $\begin{array}{l}\text { Kalau ingin membeli kopiah } \\
\text { Carilah jubah sepanjang kaki } \\
\text { Kalau ingin diberkahi Allah } \\
\text { Ayah dan bunda dijunjung tinggi }\end{array}$ & & $\sqrt{ }$ & & \\
\hline
\end{tabular}




\begin{tabular}{|c|c|c|}
\hline 7. & $\begin{array}{l}\text { Kalau kuncup bunga di taman } \\
\text { Petik sekaki bawa ke rumah } \\
\text { Kalau hidup hendakkan nyaman } \\
\text { Berbaik hati ke ayah bunda }\end{array}$ & $\sqrt{ }$ \\
\hline 8. & $\begin{array}{l}\text { Kalau kuncup bunga di pohon } \\
\text { Ambil setangkai di ujung dahan } \\
\text { Kalau hidup hendakkan rukun } \\
\text { Ayah dan bunda kita muliakan }\end{array}$ & $\sqrt{ }$ \\
\hline 9. & $\begin{array}{l}\text { Kalau hendak membuat lepat } \\
\text { Ambillah pulut dari penanggah } \\
\text { Kalau hidup hendak selamat } \\
\text { Terhadap pemimpin usah menyalah }\end{array}$ & $\sqrt{ }$ \\
\hline 10. & $\begin{array}{l}\text { Kalau hendak membuat tengguli } \\
\text { Tanakkan gula dalam belanga } \\
\text { Kalau hidup hendak terpuji } \\
\text { Terhadap pemimpin taat Setia }\end{array}$ & $\sqrt{ }$ \\
\hline 11. & $\begin{array}{l}\text { Kalau hendak membuat galah } \\
\text { Ambillah buluh ikatkan tali } \\
\text { Kalau hidup hendakkan bertuah } \\
\text { Pemimpin sejati engkau taati }\end{array}$ & $\sqrt{ }$ \\
\hline 12. & $\begin{array}{l}\text { Kalau hendak membeli kerang } \\
\text { Tengoklah kulit sebelah luar } \\
\text { Kalau hendak menjadi orang } \\
\text { Petunjuk pemimpin hendaklah dengar }\end{array}$ & $\sqrt{ }$ \\
\hline 13. & $\begin{array}{l}\text { Pasang kandil di tengah rumah } \\
\text { Terangnya sampai ke tengah halaman } \\
\text { Orang yang adil diberkahi Allah } \\
\text { Orang yang benar dirahmati Tuhan }\end{array}$ & $\sqrt{ }$ \\
\hline 14. & $\begin{array}{l}\text { Pasanglah bedil petang jumat } \\
\text { Bedil setinggar keras bunyinya }\end{array}$ & $\sqrt{ }$ \\
\hline
\end{tabular}




\begin{tabular}{|c|c|c|c|}
\hline & $\begin{array}{l}\text { Orang yang adil beroleh rahmat } \\
\text { Adil dan benar menjadi cahaya }\end{array}$ & & \\
\hline 15 & $\begin{array}{l}\text { Apa tanda orang berkatil } \\
\text { Kail tembaga dengan kelambunya } \\
\text { Apa tanda orang yang adil } \\
\text { Adil bijaksana dengan ilmunya }\end{array}$ & $\sqrt{ }$ & \\
\hline 16. & $\begin{array}{l}\text { Siapa mengail ke hulu bandar } \\
\text { Banyaklah ikan banyak lauknya } \\
\text { Siapa adil lurus dan benar } \\
\text { Hidup mati banyak eloknya }\end{array}$ & $\sqrt{ }$ & \\
\hline 17. & $\begin{array}{l}\text { Bertuah parang karena hulunya } \\
\text { Hulu dikepal elok terasa } \\
\text { Bertuah orang karena ilmunya } \\
\text { Ilmu diamalkan hidup sentosa }\end{array}$ & $\sqrt{ }$ & \\
\hline 18 & $\begin{array}{l}\text { Apalah tanda kayu meranti } \\
\text { Kayunya rampak melambai angin } \\
\text { Apalah tanda Melayu sejati } \\
\text { Ilmunya banyak belajar pun rajin }\end{array}$ & $\sqrt{ }$ & \\
\hline 19. & $\begin{array}{l}\text { Apalah tanda si kayu kelat } \\
\text { Buahnya lebat pucuknya banyak } \\
\text { Apalah tanda Melayu beradat } \\
\text { Marwahnya lekat ilmunya nampak }\end{array}$ & $\sqrt{ }$ & \\
\hline 20. & $\begin{array}{l}\text { Buah pinang masak sebiji } \\
\text { Pagi hari jatuh ke tanah } \\
\text { Bertuah orang tahu mengaji } \\
\text { Kajinya sampai membawa faedah }\end{array}$ & $\sqrt{ }$ & \\
\hline 21. & $\begin{array}{l}\text { Pucuk putat warnanya merah } \\
\text { Bila dikirai terbang melayang } \\
\text { Duduk mufakat mengandung tuah } \\
\text { Sengketa usai dendam pun hilang }\end{array}$ & & $\sqrt{ }$ \\
\hline
\end{tabular}




\begin{tabular}{|c|c|c|c|c|c|}
\hline 22. & $\begin{array}{l}\text { Kelapa gading buahnya banyak } \\
\text { Lebat berjurai di pangkal pelepah } \\
\text { Bila berunding sesama bijak } \\
\text { Kusut selesai sengketa pun sudah }\end{array}$ & & & $\sqrt{ }$ & \\
\hline 23. & $\begin{array}{l}\text { Besarlah buah kelapa gading } \\
\text { Dikerat tandan beri bertali } \\
\text { Besarlah tuah duduk berunding } \\
\text { Mufakat dapat kerja menjadi }\end{array}$ & & & & $\sqrt{ }$ \\
\hline 24 & $\begin{array}{l}\text { Kalau ke teluk pergi memukat } \\
\text { Tali temali kita kokohkan } \\
\text { Kalau duduk mencari mufakat } \\
\text { Iri dan dengki kita jauhkan }\end{array}$ & & & $\sqrt{ }$ & \\
\hline 25. & $\begin{array}{l}\text { Apalah tanda batang mengkudu } \\
\text { Daunnya rimbun sela menyela } \\
\text { Apalah tanda orang Melayu } \\
\text { Bersopan santun hidup sederhana }\end{array}$ & & & $\sqrt{ }$ & \\
\hline 26. & $\begin{array}{l}\text { Apalah tanda pisang berbuah } \\
\text { Putiknya tampak menjulur tandan } \\
\text { Apalah tanda orang bertuah } \\
\text { Hidupnya tetap dalam pertengahan }\end{array}$ & & & & $\sqrt{ }$ \\
\hline 27. & $\begin{array}{l}\text { Apa tanda kayu cendana } \\
\text { Bila diasah dibuat obat } \\
\text { Apa tanda Melayu sederhana } \\
\text { Hidupnya sederhana dunia akhirat }\end{array}$ & & & & $\sqrt{ }$ \\
\hline Jlh. & & 1 & 19 & 3 & 4 \\
\hline
\end{tabular}

\section{Nilai Edukatif yang Paling Dominan}

Berdasarkan hasil penelitian di atas, maka dapat diketahui bahwa pantun yang mengandung nilai edukatif religius terdiri dari satu buah pantun, pantun yang mengandung nilai edukatif moral terdiri dari 19 buah pantun, pantun yang 
mengandung nilai edukatif sosial terdiri dari 3 buah pantun dan pantun yang mengandung nilai edukatif budaya terdiri dari 4 buah pantun.

Pantun-pantun yang telah dianalisis di atas, akan di persentasekan dengan tujuan untuk mencari nilai edukatif yang paling dominan. Adapun hasil persentasenya adalah sebagai berikut.

$$
\begin{aligned}
& \frac{\text { Nilai Religius }}{\text { Jumlah Pantun }} \times 100 \%=\frac{1}{27} \times=4 \% \\
& \frac{\text { Nilai Moral }}{\text { Jumlah Pantun }} \times 100 \%=\frac{19}{27} \times=70 \% \\
& \frac{\text { Nilai Sosial }}{\text { Jumlah Pantun }} \times 100 \%=\frac{3}{27} \times=11 \% \\
& \frac{\text { Nilai Budaya }}{\text { Jumlah Pantun }} \times 100 \%=\frac{4}{27} \times=15 \%
\end{aligned}
$$

Berdasarkan persentase di atas, maka dapat diketahui bahwa nilai edukatif religius sebanyak 4\%, nilai edukatif moral sebanyak 70\%, nilai edukatif sosial sebanyak $11 \%$, dan nilai edukatif budaya sebanyak 15\%. Dengan demikian, maka nilai edukatif yang paling dominan dalam pantun Tunjuk Ajar Melayu Karya Tenas Effendy adalah nilai edukatif moral.

\section{B. Pembahasan}

\section{Nilai Edukatif Religius}

Dari hasil penelitian terdapat pantun religius dalam Tunjuk Ajar Melayu karya Tenas Effendy. Pantun yang dimaksud yakni sebagai berikut.

Buah kelat di tengah halaman

Pagi hari jatuh ke pangkal

\section{Bertuah umat karena beriman}

\section{Bertuah diri karena beramal}

Pantun di atas dapat diparafrasekan sebagai berikut. Ada sebuah pohon yang rasa buahnya kelat tumbuh di tengah halaman. Saat pagi menjelang buah kelat jatuh ke tanah (pangkal). Pangkal dalam pantun ini merujuk kepada pangkal pohon yang ada di tanah. Hal ini menunjukkan bahwa buah yang jatuh ke tanah adalah pertanda buah tersebut telah matang. Akan tetapi, rasanya masih terasa kelat. Dalam masyarakat Melayu, buah yang jatuh dari pohon biasanya diperam terlebih dahulu agar buah tersebut tidak lagi terasa kelat. Melalui sampiran pantun 
ini, dapat diketahui bahwa masyarakat Melayu gemar menanam pohon di lingkungan rumah mereka sebagai salah satu kegiatan untuk melestarikan alam. Selain itu, pohon-pohon tersebut juga dapat dimanfaatkan untuk kebutuhan seharihari. Diantara pohon yang sering di tanam oleh masyarakat Melayu di lingkungan rumah mereka seperti pohon kelapa, pohon pinang, pohon mangga, pohon rambutan, dan lain-lain.

Baris pantun selanjutnya yaitu merupakan isi pantun yang menjelaskan bahwa keimanan merupakan faktor yang memberikan dampak terhadap umat Muslim secara keseluruhan sedangkan amal sangat berpengaruh pada kebertuahan diri atau pribadi setiap Muslim. Pantun ini memberikan tunjuk ajar agar masyarakat Melayu selalu mendekatkan diri kepada Allah SWT. Dengan demikian, maka dapatlah dipahami bahwa kehidupan masyarakat Melayu yang sangat erat kaitannya dengan ajaran Islam. Keyakinan terhadap Tuhan Yang Maha Esa merupakan hal yang paling utama bagi masyarakat Melayu. Segala aspek kehidupan seperti budaya, adat istiadat, ataupun norma-norma sosial tidak dapat dipisahkan dari ajaran Islam. Menurut orang tua-tua Melayu, seseorang yang tidak memiliki rasa keyakinan terhadap Tuhan Yang Maha Esa maka ia tidak lagi dianggap sebagai orang Melayu. Sehingga bagi masyarakat Melayu hidup bertuah dapat diperoleh melalui rasa keyakinan terhadap Tuhan Yang Maha Esa. Namun demikian, tidaklah bermakna bahwa masyarakat Melayu menolak masyarakat yang tidak satu akidah, bahkan sebaliknya menganjurkan untuk hidup saling hormat menghormati, saling menghargai, dan sebagainya.

Nilai edukatif dalam pantun ini mengajarkan tentang pentingnya keyakinan kepada Tuhan Yang Maha Esa terhadap kesuksesan (kebertuahan) dalam hidup merupakan isi dari pantun untuk mendidik generasi Melayu agar tetap taat menjalankan kehidupan sesuai dengan ajaran atau syari'at Islam. Hal ini merupakan bentuk edukasi yang diberikan orang tua kepada anaknya dalam nyanyian menidurkan anak. Orang tua-tua Melayu sudah memberikan didikan religius sejak dini kepada anak-anak keturunannya. Nilai inilah yang sejak dahulu mampu mewujudkan kerukunan hidup antar umat beragama di bumi Melayu. 
Berdasarkan penjelasan di atas, maka pantun ini dikategorikan sebagai pantun yang memiliki nilai edukatif religius berdasarkan aspek keyakinan.

\section{Nilai Edukatif Moral}

Adapun nilai edukatif moral yang terdapat dalam pantun Tunjuk Ajar Melayu karya Tenas Effendy dapat diketahui melalui salah satu pantun berikut.

\section{Apalah tanda punak berbuah}

Dari jauh nampak putiknya

Apalah tanda anak bertuah

\section{Budi senonoh nampak cerdiknya}

Pantun di atas dapat diparafrasekan sebagai berikut. Buah punak memiliki tanda apabila akan berbuah. Tanda yang dimaksud adalah putik punak yang lebat sehingga dapat terlihat dari kejauhan. Selain buah punak, buah-buahan lain juga memiliki tanda yang sama apabila akan berbuah. Hanya saja dalam sampiran pantun ini digunakan kata "punak" agar memiliki rima yang sama dengan isi pantun pada baris ke tiga yaitu "anak" yang menjadi sasaran dari si pemantun yakni orang tua. Saat melakukan nyanyian menidurkan anak, orang Melayu selalu memberikan contoh dengan benda-benda atau hal-hal yang ada di sekitarnya.

Baris pantun selanjutnya merupakan isi pantun yang menjelaskan tanda atau ciri-ciri anak yang bertuah adalah memiliki budi pekerti yang baik sehingga terlihat bahwa ia memiliki akal yang cerdas. Pantun ini menunjukkan edukasi orang tua kepada anaknya agar menjadi anak yang bertuah. Orang tua-tua mengatakan bahwa sebaik-baik manusia adalah mereka yang memiliki keseimbangan antara pengetahuan dengan keimanan. Inilah yang disebut sebagai "orang bertuah" dan menjadi idaman setiap orang Melayu. Hal ini tentu juga menjadi harapan bagi para orang tua Melayu agar anak-anaknya dapat menjadi anak-anak yang bertuah. Dengan memiliki budi pekerti yang baik dan memiliki pengetahuan yang luas maka seorang anak dapat dikatakan sebagai anak yang bertuah.

Budi pekerti yang dimaksud dalam pantun merujuk kepada akhlak-akhlak mulia yang sesuai dengan ajaran Islam, seperti kejujuran, sifat rendah hati, sifat 
pemaaf, ikhlas, dan sebagainya. Semua akhlak atau budi pekerti tersebut merupakan bentuk ketakwaan kepada Tuhan Yang Maha Esa. Dalam Islam diajarkan, bahwa setiap kebaikan yang dilakukan seorang Muslim akan mendapat pahala yang dilipatgandakan menjadi sepuluh kebaikan. Akan tetapi apabila satu kejahatan yang dilakukan maka dosanya hanya dihitung satu kejahatan saja. Islam mengajarkan bahwa hasil dari kebaikan yang dilakukan tidak hanya mendapat satu tetapi sepuluh kebaikan. Melalui pantun ini, dapat dipahami bahwa orang tua Melayu lebih mendahulukan didikan tingkah laku dibandingkan dengan intelektual kepada anak-anaknya.

Bagi orang tua Melayu, kecerdikan atau kepandaian seseorang anak dapat dilihat dari tingkah laku atau tutur katanya. Meskipun ia memiliki pengetahuan yang luas tentang berbagai hal, tetapi tidak diimbangi dengan budi pekerti yang baik maka tidak dapat dikatakan seorang anak tersebut memiliki kecerdasan. Orang yang cerdas tidak akan melakukan tindakan buruk yang dapat merugikan dirinya sendiri bahkan orang lain. Oleh karena itu, untuk menjadi anak yang bertuah harus bisa memiliki budi pekerti yang diimbangi dengan kecerdasan yang memadai.

Nilai edukatif dalam pantun ini berkaitan dengan budi pekerti yang menjadi acuan dalam bertingkah laku. Budi pekerti ini sudah diajarkan oleh orang tua Melayu kepada anaknya sejak ia berada dalam ayunan. Dengan demikian, maka pantun ini dikategorikan sebagai pantun yang memiliki nilai edukatif moral berdasarkan aspek budi pekerti.

\section{Nilai Edukatif Sosial}

Nilai edukatif sosial dalam pantun Tunjuk Ajar Melayu karya Tenas Effendy, salah satunya sebagai berikut.

Kelapa gading buahnya banyak

Lebat berjurai di pangkal pelepah

Bila berunding sesama bijak

Kusut selesai sengketa pun sudah 
Pantun di atas dapat diparafrasekan sebagai berikut. Kelapa gading memiliki buah yang banyak. Buah kelapa yang banyak tersebut tumbuh berjurai atau berumbai-rumbai di pangkal pelepahnya. Melalui sampiran pantun ini masyarakat Melayu diajarkan untuk merapatkan barisan dengan memperkokoh hubungan persaudaraan seperti kelapa gading yang tumbuh lebat hingga berumbai-rumbai.

Baris pantun selanjutnya merupakan isi pantun yang mengatakan bahwa berunding atau bermusyawarah yang dilakukan dengan bijak dapat memperbaiki hubungan yang tidak harmonis menjadi rukun kembali dan sengketa, perselisihan, ataupun pertikaian dapat diselesaikan. Dalam hubungan bermasyarakat ataupun berkeluarga tidak jarang terjadi permasalahan-permasalahan yang dapat menimbulkan permusuhan, perselisihan, dan pertikaian. Penyelesaian masalah dengan cara yang tidak tepat dapat memperburuk hubungan antar sesama sehingga persatuan dan kesatuan menjadi longgar dan terpecah belah.

Pantun ini mengandung nilai edukatif yang mengajarkan masyarakat untuk melakukan musyawarah atau berunding dalam menyelesaikan setiap permasalahan yang terjadi, baik dalam lingkungan karib kerabat ataupun masyarakat luas. Berunding dengan bijak merupakan salah satu bentuk musyawarah yang dilakukan berdasarkan adat istiadat. Dalam pelaksanaanya, setiap anggota yang bermusyawarah bebas mengeluarkan pendapat dan tidak ada paksaan dengan tetap mengutamakan persatuan dan kesatuan serta menghormati pendapat dan pikiran orang lain. Oleh karena itu, dalam masyarakat Melayu, orang-orang yang terlibat dalam musyawarah atau perundingan hanyalah orangorang yang dituakan atau orang-orang yang memiliki wewenang dalam masalah tersebut.

Pantun ini juga mengajarkan tentang adat istiadat yang harus diperhatikan oleh masyarakat Melayu dalam melakukan musyawarah atau perundingan. Musyawarah yang dilakukan tanpa adat istiadat dapat menimbulkan konflik baru sehingga masalah dapat bertambah. Melalui pantun ini, dapat diketahui bahwa salah satu bentuk adat istiadat dalam berunding atau bermusyawarah harus dilakukan dengan bijak. Sikap bijak yang dimiliki setiap anggota yang berunding 
atau bermusyawarah akan menghasilkan keputusan bersama dan menjadi tanggung jawab bersama, sehingga keadilan dan kebenaran dapat dilaksanakan dan tidak ada pihak yang dirugikan. Berdasarkan penjelasan di atas, maka pantun ini mengandung nilai edukatif sosial sesuai dengan hubungan dengan sesama.

\section{Nilai Edukatif Budaya}

Nilai edukatif budaya yang terdapat dalam pantun Tunjuk Ajar Melayu Karya Tenas Effendy adalah sebagai berikut.

Pucuk putat warnanya merah

Bila dikirai terbang melayang

Duduk mufakat mengandung tuah

Sengketa usai dendam pun hilang

Pantun di atas dapat diparafrasekan sebagai berikut. Pucuk dari pohon putat memiliki warna merah. Bila pohonnya dikiraikan atau digoyangkan pucuk tersebut akan berterbangan. Sampiran dalam pantun ini mengajarkan bahwa jika kekuatan persatuan di antara masyarakat lemah, maka akan mudah terjadi perpecahan dan permusuhan. Hal itu dapat dihindari melalui tunjuk ajar yang terkandung dalam isi pantun.

Baris pantun selanjutnya yang merupakan isi pantun mengatakan bahwa duduk untuk mufakat mengandung tuah atau faedah yang dapat menyelesaikan berbagai sengketa sehingga tidak ada lagi rasa dendam. Pantun ini memberikan tunjuk ajar bahwa setiap persengketaan ataupun perselisihan yang terjadi dalam masyarakat dapat diselesaikan dengan mufakat. Kegiatan mufakat yang dilakukan dengan cara yang baik yakni sesuai dengan adat istiadat akan menghasilkan keputusan yang bijaksana karena keputusan tersebut diambil berdasarkan kesepakatan bersama dengan mempertimbangkan kepentingan bersama. Mufakat sudah menjadi adat bagi masyarakat Melayu untuk menyelesaikan segala permasalahan, baik dilingkungan keluarga ataupun masyarakat.

Keputusan mufakat yang merupakan kesepakatan bersama dapat menghilangkan rasa dendam dan benci diantara orang-orang yang berselisih 
paham. Hal itu dikarenakan, dalam pelaksanaanya mufakat lebih mengutamakan kepentingan bersama, bukan kepentingan perseorangan sehingga semua pihak tidak akan merasa dirugikan atau dilebihkan. Dalam mufakat, semua anggota diperlakukan dengan cara yang sama. Dengan demikian, maka ketenteraman dan kedamaian hidup bermasyarakat dapat dijaga dipertahankan keberadaannya.

Pantun ini mengandung nilai edukatif yang mengajarkan kepada masyarakat untuk membudayakan mufakat sebagai solusi dalam setiap perselisihan, persengketaan, ataupun permusuhan yang terjadi dalam anggota masyarakat. Sehingga akan ditemukan jalan tengah yang tidak memihak. Berdasarkan penjelasan ini maka pantun di atas mengandung nilai edukatif budaya berdasarkan aspek adat/kebiasaan.

\section{PENUTUP}

Berdasarkan hasil penelitian dapat disimpulkan sebagai berikut.

1. Pantun dalam Tunjuk Ajar Melayu karya Tenas Effendy termasuk jenis pantun nasehat. Pantun-pantun tersebut merupakan media tunjuk ajar atau media edukasi yang dilakukan oleh orang-orang tua Melayu sebagai bentuk didikan agar anak-anak keturunannya dapat menjadi orang bertuah. Pantun dapat menjadi cerminan masyarakat berdasarkan kalimat-kalimat yang digunakan, sehingga dapat dianalisis dengan kajian sosiologi sastra.

2. Nilai-nilai edukatif yang terdapat dalam pantun Tunjuk Ajar Melayu karya Tenas Effendy yaitu nilai edukatif religius 1 buah pantun, nilai edukatif Smoral 19 buah pantun, nilai edukatif sosial 3 buah pantun, dan nilai edukatif budaya 4 buah pantun. Dari data tersebut, maka dapat diketahui bahwa nilai edukatif yang paling dominan yaitu nilai edukatif moral. 


\section{DAFTAR PUSTAKA}

Aminuddin, dkk. 2006. Membangun Karakter dan Kepribadian melalui Pendidikan Agama Islam. Yogyakarta: Graha Ilmu.

Effendy, Tenas. 2005. Pantun Nasehat. Edisi Ke-2. Yogyakarta: Adicita Karya Nusa.

Effendy, Tenas. 2006. Tunjuk Ajar Melayu. Edisi Ke-2. Yogyakarta: Balai Kajian dan Pengembangan Budaya Melayu.

Endraswara, Suwardi. 2011. Metodologi Penelitian Sosiologi Sastra. Yogyakarta: Caps.

Ganie, Tajuddin Noor. 2015. Buku Induk Bahasa Indonesia. Yogyakarta: Araska.

Ismawati, Esti. 2012. Ilmu Sosial dan Budaya Dasar. Yogyakarta: Ombak. 